\title{
SARS-CoV-2 spike protein inhibits growth of prostate cancer: a potential role of the COVID-19 vaccine killing two birds with one stone
}

\author{
Bradley D. Johnson ${ }^{1} \cdot$ Ziwen Zhu $^{2} \cdot$ Marco Lequio $^{1,2}$ - Coby G. D. Powers ${ }^{2} \cdot$ Qian Bai $^{2} \cdot$ Huaping Xiao $^{2}$. \\ Emerson Fajardo ${ }^{2} \cdot$ Mark R. Wakefield $^{2} \cdot$ Yujiang Fang ${ }^{1,2}$
}

Received: 10 November 2021 / Accepted: 13 December 2021 / Published online: 20 January 2022

(c) The Author(s), under exclusive licence to Springer Science+Business Media, LLC, part of Springer Nature 2021

\begin{abstract}
To investigate the effects of isolated SARS-CoV-2 spike protein on prostate cancer cell survival. The effects of SARS-CoV-2 spike protein on LNCaP prostate cancer cell survival were assessed using clonogenic cell survival assay, quick cell proliferation assay, and caspase-3 activity kits. RT-PCR and immunohistochemistry were performed to investigate underlying molecular mechanisms. SARS-CoV-2 spike protein was found to inhibit prostate cancer cell proliferation as well as promote apoptosis. Further investigation revealed that anti-proliferative effects were associated with downregulation of the pro-proliferative molecule cyclin-dependent kinase 4 (CDK4). The increased rate of apoptosis was associated with the upregulation of pro-apoptotic molecule Fas ligand (FasL). SARS-CoV-2 spike protein inhibits the growth of LNCaP prostate cancer cells in vitro by a two-pronged approach of downregulating the expression of CDK4 and upregulating FasL. The introduction of SARS-CoV-2 spike protein into the body via COVID-19 vaccination may have the potential to inhibit prostate cancer in patients. This potential beneficial association between COVID-19 vaccines and prostate cancer inhibition will require more extensive studies before any conclusions can be drawn about any in vivo effects in a human model.
\end{abstract}

Keywords SARS-CoV-2 $\cdot$ Spike protein $\cdot$ Prostate cancer $\cdot$ FasL $\cdot$ CDK $4 \cdot$ Proliferation $\cdot$ Apoptosis

\section{Introduction}

The severe acute respiratory syndrome coronavirus 2 (SARS-CoV-2) has had devastating consequences worldwide with millions of lives lost since it was first identified in December 2019. A member of the Coronaviridae family, SARS-CoV-2 is an enveloped positive-sense RNA virus that attaches and fuses to host cells via a spike protein on its outer envelope [1]. This spike protein has been the target of many vaccines since it is required for the virus to continue to infect host cells via interaction with the ACE2 receptor [2]. The first vaccines approved for emergency use by the

Yujiang Fang

yujiang.fang@dmu.edu

1 Department of Microbiology, Immunology \& Pathology, Des Moines University College of Osteopathic Medicine, Des Moines, IA 50312, USA

2 Department of Surgery, University of Missouri School of Medicine, Columbia, MO 65212, USA
US Food and Drug Administration use mRNA as the means of introducing the SARS-CoV-2 spike protein to the body's immune system. The effectiveness of the response hinges on the body's ability to produce the spike protein from the introduced mRNA transcript, recognize the foreign antigen, and produce spike protein-specific antibodies. Evaluation of the COVID-19 vaccines' long-term effectiveness and safety is ongoing, particularly in light of emerging variants of the virus $[3,4]$.

A particularly vulnerable subpopulation is cancer patients due to their immunocompromised state which can be attributed to the primary disease process or secondary to the treatment they are receiving [5, 6]. This results in increased susceptibility to contracting COVID-19, increased severity of the disease, and a weaker immune response to vaccines [7, 8]. Most phase 3 clinical trials excluded volunteers with cancer resulting in limited data for this group, but many experts still recommend that cancer patients should receive the vaccine since the potential benefits outweigh the wellestablished risks of contracting COVID-19 [9]. Prostate cancer accounts for the highest amount of new cancer diagnoses 
in men in the U.S. and it is also estimated to have the second highest mortality rate. It is estimated that in 2021 there will be 248,530 new cases of prostate cancer [10].

As the spike protein is the target of choice for vaccineinduced immunity, it is of particular interest to investigate what potential effects SARS-CoV-2 spike protein may have on prostate cancer cells. Our study set out to determine whether the presence of isolated spike protein had a significant effect on the survival of $\mathrm{LNCaP}$ prostate cancer cells grown in vitro and to investigate the mechanism of such action.

\section{Materials and methods}

\section{Tumor cell line}

The human prostate cancer cell line $\mathrm{LNCaP}$ was acquired from Dr. Lubahn (University of Missouri, Columbia, MO) and cultured in DMEM (Invitrogen, Carlsbad, CA, USA) for preservation, supplemented with $10 \%$ heat-inactivated FBS and $1 \%$ penicillin-streptomycin (Invitrogen). The $\mathrm{LNCaP}$ cells were incubated at $37{ }^{\circ} \mathrm{C}$ in a humidified $5 \% \mathrm{CO}_{2}$ incubator. Upon reaching $70 \%$ confluence the cells underwent the experimental treatment regimens.

\section{Treatment with SARS-CoV-2 SP}

For the clonogenic survival assay (CSA) LNCaP cells at 70\% confluence were treated with SARS-CoV-2 SP (BioLegend, San Diego, CA) at the concentrations of $20 \mathrm{ng} / \mathrm{mL}, 50 \mathrm{ng} /$ $\mathrm{mL}$, and $200 \mathrm{ng} / \mathrm{mL}$ for $72 \mathrm{~h}$, along with a control group with only medium. All other experiments utilized LNCaP cells treated with SARS-CoV-2 SP at $50 \mathrm{ng} / \mathrm{mL}$ for $72 \mathrm{~h}$, and a control that consisted of LNCaP cells in medium alone for the same length of time.

\section{Clonogenic survival assay (CSA)}

Clonogenic survival assay was performed as previously described [11-14]. LNCaP cells were retrieved from culture flasks with TrypLE Express (Invitrogen), suspended in phosphate-buffered saline, and tallied with a hemocytometer. 1000 cells were plated in triplicate in $60-\mathrm{mm}$ Corning petri dishes and incubated at $37{ }^{\circ} \mathrm{C}$ in a humidified $5 \% \mathrm{CO}_{2}$ incubator. On day 5 fresh media was added. On day 9 the LNCaP cells were fixed in $10 \%$ formaldehyde and stained with $0.05 \%$ crystal violet. $\mathrm{LNCaP}$ colonies in the treatment groups were counted and expressed as a percentage of total colonies observed in the control groups.

\section{Quick cell proliferation assay}

LNCaP cell proliferation was studied using the quick cell proliferation assay kit (BioVision). An increase in the number of viable cells resulted in increased mitochondrial dehydrogenase activity, leading to increased production of formazan dye which was quantified by spectrophotometer. The detailed procedure can be reviewed in previous studies [11-13].

\section{Immunohistochemistry (IHC)}

The IHC staining protocol used for proliferative cell nuclear antigen (PCNA), Fas ligand (FasL), and cyclindependent kinase 4 (CDK4) has been described in previous studies [11-14]. Antibodies for FasL (catalog number sc-834) and CDK4 (catalog number sc-260) were acquired from Santa Cruz Biotechnology, CA. Dilutions of 1:200 and 1:500 were used for primary and secondary antibodies, respectively. PCNA-positive cells were manually counted under randomly selected 3-5 high-power fields. MetaMorph 6.3r6 image analysis software was used for counting as well as assessing the average staining intensity for proteins within the LNCaP cell-covered area. Results were expressed as the average integrated immunostaining intensity of 3 slides \pm SEM compared to control cell intensity.

\section{Reverse transcription-polymerase chain reaction (RT-PCR)}

LNCaP cells were prepared for RT-PCR by washing with phosphate-buffered saline, homogenizing in TRIzol (Invitrogen), and extracting RNA. Nanodrop was used to determine RNA concentration. $1 \mu \mathrm{g}$ RNA was reverse transcribed as detailed previously [11-14]. Glyceraldehyde-3-phosphate dehydrogenase (GAPDH) gene was used as an internal control to verify that the same amount of RNA had been amplified. The primer sequences for GAPDH, pro- and anti-proliferative molecules, and pro- and anti- apoptotic molecules are included in Table 1.

\section{TUNEL staining}

Apoptosis was measured by terminal deoxynucleotidyl transferase-mediated dUTP nick-end labeling (TUNEL) assay via a Chemicon ApopTag kit. This procedure was performed as previously described [11-14]. Apoptotic cells were quantified by manually counting all LNCaP cells within 5-6 randomly selected high-power fields at 400X magnification, 
Table 1 Primer sequences used in RT-PCR

\begin{tabular}{|c|c|c|}
\hline Name & Sense & Antisense \\
\hline p18 & 5'-CCTGATCGTCAGGACCCTAA-3' & 5'-TTATTGAAGATTTGTGGCTCC-3' \\
\hline $\mathrm{p} 21$ & 5'-CACCCTAGTTCTACCTCAGGCA-3' & 5'-ACТCССССАТCATATAССССТ-3' \\
\hline $\mathrm{p} 27$ & 5'-ACGGGAGCCCTAGCCTGGAGC-3' & 5'-TGCCCTTCTCCACCTCTTGCC-3' \\
\hline $\mathrm{p} 53$ & 5'-TGGCCATCTACAAGCAGTCACA-3' & 5'-GCAAATTTCCTTCCACTCGGAT-3' \\
\hline Cyclin B & 5'-CCATTATTGATCGGTTCATGCAGA-3' & 5'-CTAGTGGAGAATTCAGCTGTGGTA-3' \\
\hline Cyclin D & 5'-GGATGCTGGAGGTCTGCGAGGAAC-3' & 5'-GAGAGGAAGCGTGTGAGGCGGTAG-3' \\
\hline Cyclin E & 5'-GGAAGGCAAACGTGACCGTT-3' & 5'-GGGACTTAAACGCCACTTAA-3' \\
\hline CDK4 & 5'-ATGGCTACCTCTCGATATGAGC-3' & 5'-CTCAAAAGCCTCCAGTCGCCTC-3' \\
\hline Fas & 5'-ACTTGGGGTGGCTTTGTCTT-3' & 5'-GGATGATAGTCTGAATTTTCTCTG-3' \\
\hline FasL & 5'-GCCTGTGTCTCCTTGTGA-3' & 5'-GCCACCCTTCTTATACTT-3' \\
\hline TRAILR1 & 5'-AGAGGGATGGTCAAGGTCAA-3' & 5'-GAGTCAAAGGGCACGATGTT-3' \\
\hline TRAIL & 5'-AGTCTCTCTGTGTGGCTGTA-3' & 5'-TGTCTATCAAGTGCTCATTT-3' \\
\hline FLIP & 5'-AATTCAAGGCTCAGAAGCGA-3' & 5'-GGCAGAAACTCTGCTGTTCC-3' \\
\hline Bcl-2 & 5'-GTGGAGGAGCTCTTCAGGGA-3' & 5'-AGGCACCCAGGGTGATGCAA-3' \\
\hline Survivin & 5'-AGCССТTТСТCAAGGACCAC-3' & 5'-GCACTTTCTTCGCAGTTTCC-3' \\
\hline
\end{tabular}

utilizing MetaMorph image analysis software. TUNELpositive cells were expressed as a percentage of total cells.

\section{Measurement of caspase-3 activity}

Apoptotic activity was also evaluated via caspase-3 activity. A BioVision caspase-3/CPP32 colorimetric assay kit was used to evaluate caspase- 3 activity in the LNCaP cells. The procedure was documented previously [11-14].

\section{Statistics}

All experiments were performed in triplicate to ensure accuracy. Statistical analysis of the data was performed using an unpaired two-tailed $t$ test. A $p$-value of $<0.05$ was used to determine if the data were statistically significant.

\section{Results}

\section{Effect of SARS-CoV-2 spike protein on LNCaP cell survival}

In order to evaluate the effect of SARS-CoV-2 SP on the survival of LNCaP cells, the cells were treated for $72 \mathrm{~h}$ with SP at varying concentrations alongside a control that consisted of medium alone. The clonogenic survival assay indicated a decrease in LNCaP cell survival in the samples that included SARS-CoV-2 SP. SP concentrations of $20 \mathrm{ng} / \mathrm{mL}, 50 \mathrm{ng} / \mathrm{mL}$, and $200 \mathrm{ng} / \mathrm{mL}$ each showed significant decreases in colony count (Fig. 1A, $p<0.05$ ). The colony count percentages were $49 \pm 4 \%, 41 \pm 3 \%$, and $45 \pm 11 \%$ for the SP concentrations $20 \mathrm{ng} / \mathrm{mL}, 50 \mathrm{ng} / \mathrm{mL}$, and $200 \mathrm{ng} / \mathrm{mL}$, respectively.
This suggests that $20 \mathrm{ng} / \mathrm{mL}$ of SP appears to effectively inhibit the growth of LNCaP cells and increasing the concentration to $200 \mathrm{ng} / \mathrm{mL}$ does not significantly increase the inhibitory effect. All subsequent assays utilized the $50 \mathrm{ng} /$ mL SP concentration as the treatment group, as this had the most pronounced decrease in cell colony count.

The optical density values obtained from a Quick Cell Proliferation Assay also demonstrated a significant reduction in optical density (OD) values between the control group and the cells treated with SP $(50 \mathrm{ng} / \mathrm{mL})$ (Fig. 1B). PCNA expression was also evaluated via IHC as an indicator of LNCaP cell proliferation. The SP $(50 \mathrm{ng} / \mathrm{mL})$ group showed a significantly decreased relative intensity compared to the control group (Fig. 1C, $p<0.05$ ). These findings suggest that SARS-CoV-2 SP has a significant negative effect on the proliferation of $\mathrm{LNCaP}$ cells.

\section{SARS-CoV-2 spike protein downregulates pro-proliferative molecule CDK4}

The mechanism of decreased LNCaP cell survival was examined using RT-PCR to evaluate the mRNA expression of key molecules involved in the cell cycle. The expression of several pro-proliferative molecules (cyclin B, cyclin D, cyclin E, and CDK4) and anti-proliferative molecules (p18, p21, p27, and p53) were evaluated and the relative levels of expression were compared between the $50 \mathrm{ng} / \mathrm{mL} \mathrm{SP}$ and control groups. There was a significant decrease in CDK4 expression in the LNCaP cells treated with $50 \mathrm{ng} / \mathrm{mL} \mathrm{SP}$ compared to the controls (Fig. 2A, $p<0.05$ ). IHC staining was also performed to evaluate the relative intensity of the LNCaP cells in the $50 \mathrm{ng} / \mathrm{mL}$ group. A significant decrease in staining intensity was observed in the $50 \mathrm{ng} / \mathrm{mL}$ SP group 

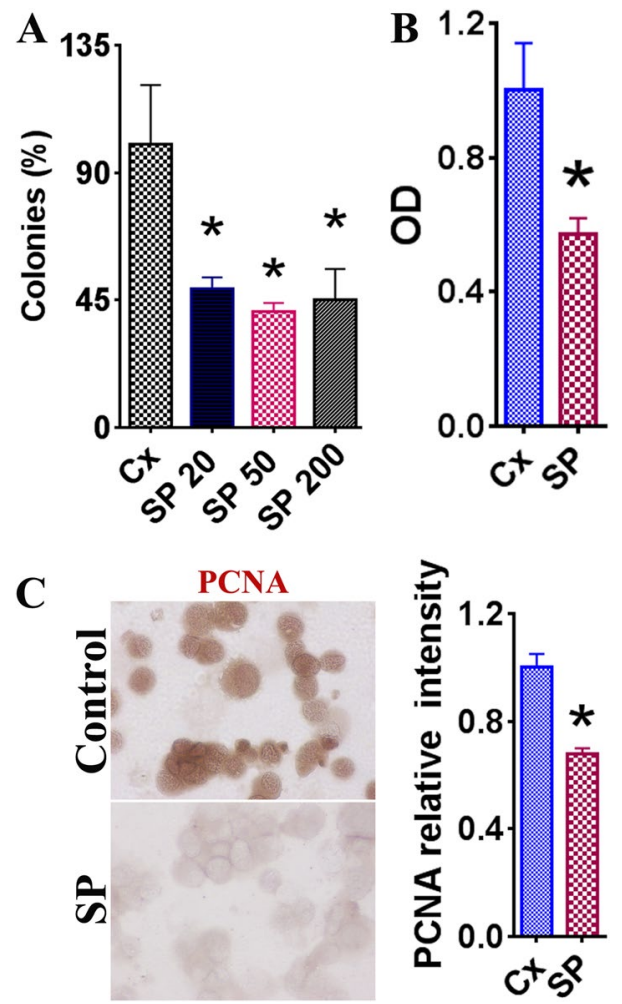

Fig. 1 The effect of SARS-CoV-2 spike protein on LNCaP cell survival. Results with statistically significant $(p<0.05)$ differences from the control group are indicated by asterisk (*). A Clonogenic survival assay for LNCaP cells treated with various concentrations of spike protein (SP): $20 \mathrm{ng} / \mathrm{mL}, 50 \mathrm{ng} / \mathrm{mL}, 200 \mathrm{ng} / \mathrm{mL}$ for $72 \mathrm{~h}$. Control consisted of medium alone for the same timeframe. Colony numbers were quantified as a total percentage of colonies in the control group. B Evaluation of the control group and SP (50 ng/mL) using a cell proliferation kit. Results reflect two independent experiments and are expressed as the average optical density (OD) plus the standard error of the mean (SEM) between control and SP groups. C IHC PCNA staining images displaying relative intensity between the control group (medium only) and the SP group $(50 \mathrm{ng} / \mathrm{mL})$, treated for $72 \mathrm{~h}$ prior to staining. PCNA+ cells were counted using MetaMorph software. PCNA+ cell counting was performed using a random selection of 5-6 high-power fields from three slides. Images are at original $\times 400$ magnification

versus the control group (Fig. 2B). These findings suggest that suppression of LNCaP cell proliferation by SARSCoV-2 SP may be through downregulation of CDK4.

\section{SARS-CoV-2 spike protein promotes apoptosis in LNCaP cells}

Decreased proliferation is only one side of the coin, as cell survival is also determined by the rate of apoptosis. To determine the role of SARS-CoV-2 SP in apoptosis of LNCaP cells, TUNEL staining was performed (Fig. 3A). The TUNEL + cells in the SP $50 \mathrm{ng} / \mathrm{mL}$ group had a significantly higher percentage (Fig. 3B, $p<0.05$ ). These
A
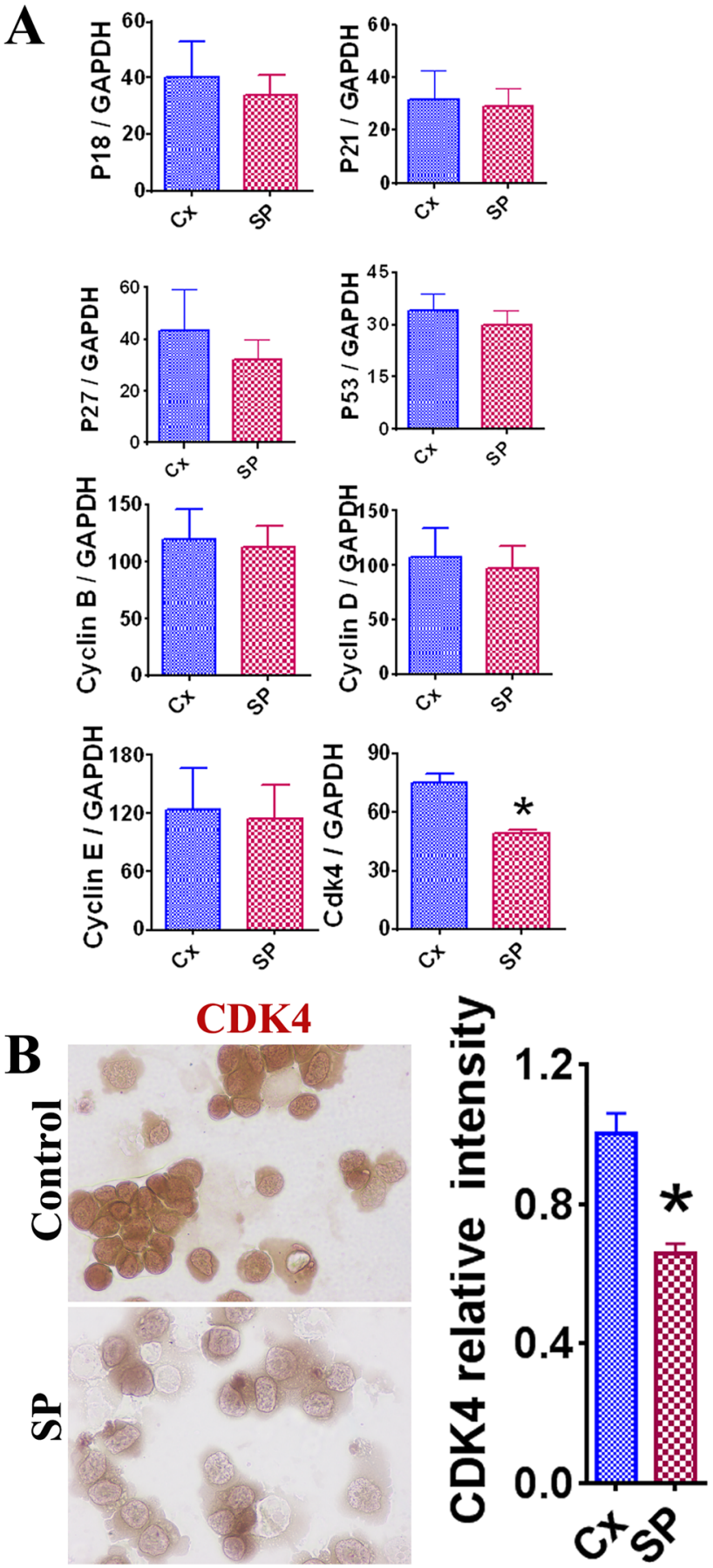

Fig. 2 The effect of SARS-CoV-2 SP $(50 \mathrm{ng} / \mathrm{mL})$ on expression of key pro- and anti- proliferative molecules in LNCaP cells. Statistically significant results are indicated by asterisk $(*)(p<0.05)$. A Comparison of mRNA expression levels in pro- and anti-proliferative molecules in LNCaP cells. Pro-proliferative molecules included cyclin B, cyclin D, cyclin E, and CDK4. Anti-proliferative molecules included p18, p21, p27, and p53. GAPDH was used as an internal control for comparison of expression levels. Each experiment was completed in triplicate and recorded on the graphs as a mean ratio of molecule densitometric Units/ GAPDH + SEM $(\times 100)$. B Evaluation of CDK4 expression in LNCaP cells via IHC staining. IHC images appear as original magnification of 400X. Relative staining intensity was evaluated via MetaMorph image software analysis of 3-5 randomly selected high-power fields of three slides 


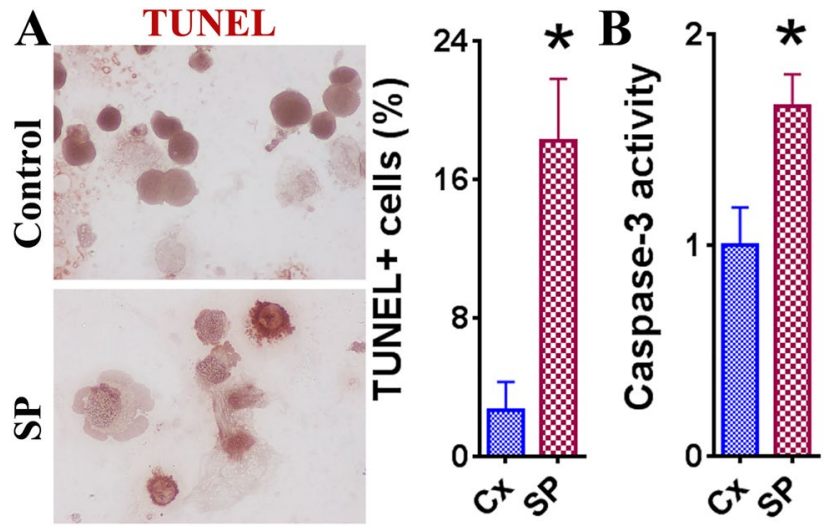

Fig. 3 Effect of SARS-CoV-2 SP (50 ng/mL) on LNCaP cell apoptosis. Statistically significant differences in TUNEL + cells and relative caspase- 3 activity between the treatment group (SP $50 \mathrm{ng} / \mathrm{mL}$ ) and control group (medium alone) are indicated with an asterisk $(*)$ $(p<0.05)$. A TUNEL staining images and TUNEL + cell percentage comparison between $50 \mathrm{ng} / \mathrm{mL}$ SP treatment and control groups. IHC images appear at original $\times 400$ magnification. TUNEL + cells were evaluated using MetaMorph image software on 3-5 randomly selected high-power fields of 3 slides. B Caspase- 3 activity of control and SP $50 \mathrm{ng} / \mathrm{mL}$ groups of LNCaP cells via caspase-3 activity kit. The experiment was performed in triplicate and results are expressed as the mean caspase- 3 activity compared to the controls + SEM

findings support the notion that SP promotes the apoptosis of LNCaP cells. Additionally, the relative caspase-3 activity of LNCaP cells was evaluated to further investigate the apoptotic activity. Consistent with the previous findings, there was a significant increase of caspase- 3 activity in the $50 \mathrm{ng} / \mathrm{mL}$ SP group compared to the control group (Fig. 3B, $p<0.05$ ). These results suggest that SARSCoV-2 SP also affects LNCaP cell survival by promoting apoptosis.

\section{Effect of SARS-CoV-2 spike protein on the pro-apoptotic molecule FasL}

To examine the mechanism of apoptosis of LNCaP cells in the presence of SARS-CoV-2 SP, RT-PCR was performed to measure the expression of various pro-apoptotic molecules (Fas, FasL, TRAILR1, and TRAIL) and anti-apoptotic molecules (FLIP, Bcl-2, and survivin). A significant increase in FasL expression was observed in the $50 \mathrm{ng} / \mathrm{mL}$ SP group (Fig. 4A, $p<0.05$ ). IHC staining was performed to further evaluate the expression of FasL. Significantly increased FasL intensity was observed in the $50 \mathrm{ng} / \mathrm{mL}$ SP group relative to the control group (Fig. $4 \mathrm{~B}, p<0.05$ ). The IHC results further support that the presence of SARS-CoV-2 SP promotes upregulation of FasL. These findings suggest that SARS-CoV-2 SP induces apoptosis via upregulation of the pro-apoptotic molecule FasL.
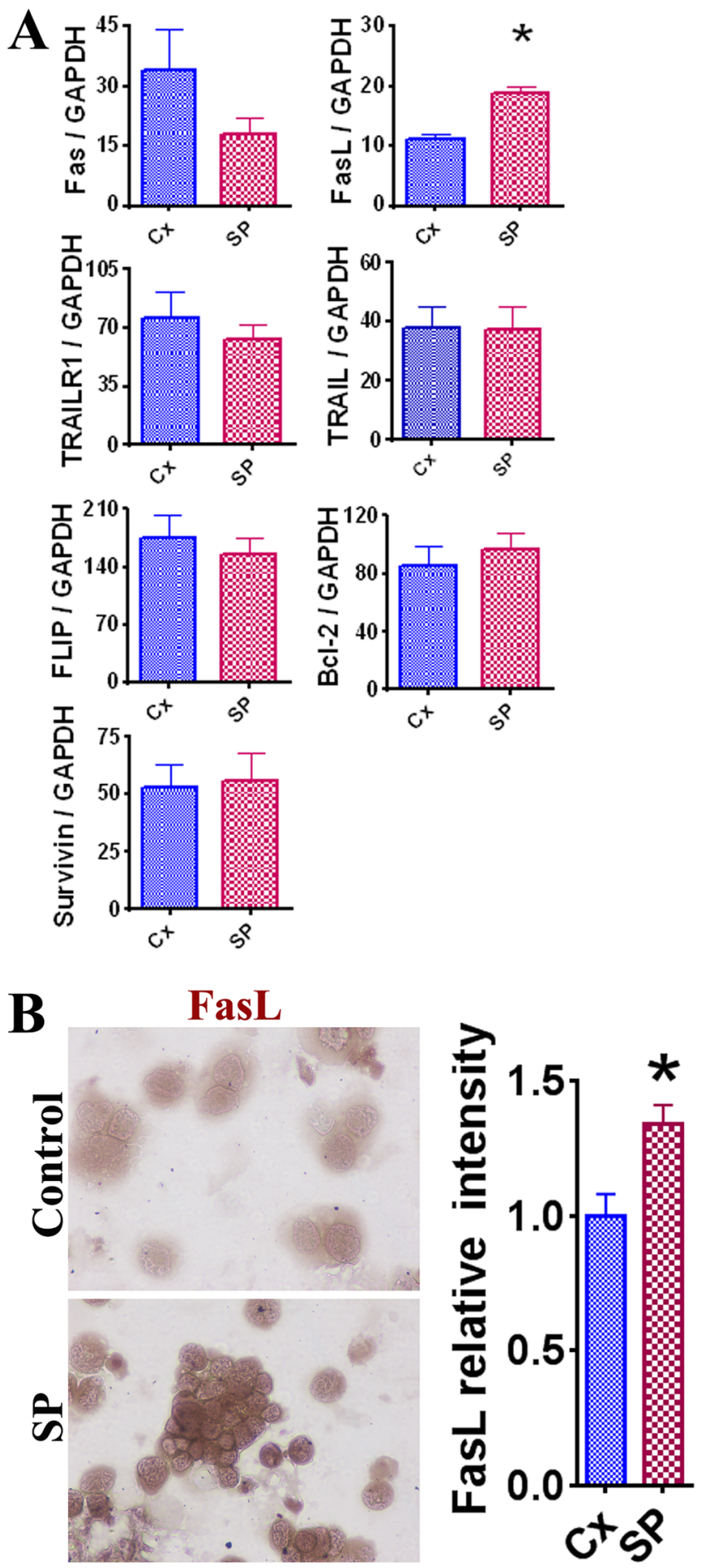

Fig. 4 The effect of SARS-CoV-2 SP $(50 \mathrm{ng} / \mathrm{mL})$ on expression of key pro- and anti-apoptotic molecules in LNCaP cells. Statistically significant results are indicated by asterisk $(*)(p<0.05)$. A Comparison of mRNA expression levels in pro- and anti-apoptotic molecules in LNCaP cells. Pro-apoptotic molecules included Fas, FasL, TRAILR1, and TRAIL. Anti-apoptotic molecules included FLIP, Bcl-2, and survivin. GAPDH was used as an internal control for comparison of expression levels. Each experiment was completed in triplicate and recorded on the graphs as a mean ratio of molecule densitometric Units/GAPDH + SEM $(\times 100)$. B Evaluation of FasL expression in LNCaP cells via IHC staining. The IHC images appear as original $\times 400$ magnification. Relative staining intensity was evaluated via MetaMorph image software analysis of 3-5 randomly selected high-power fields of three slides 


\section{Discussion}

This study investigated the effects of SARS-CoV-2 spike protein on prostate cancer growth in vitro. The results indicate that spike protein reduces the survival of prostate cancer cells via a two-pronged approach which simultaneously limits cell proliferation and induces apoptosis. It appears that the reduction in LNCaP cell survival is mediated by mechanisms that suppress the expression of pro-proliferative molecule CDK4 and upregulate the expression of pro-apoptotic molecule FasL.

Cyclin-dependent kinase 4 (CDK4) is one of the key molecules that are involved in regulating the cell cycle. Dysregulation among these molecules often results in inappropriate cell proliferation, which makes dysfunctional CDK-pathways a common finding in many cancers $[15,16]$. An emerging therapeutic strategy in cancer treatment is the use of CDK inhibitors which would downregulate the overactive pro-proliferative molecules such as CDK4. A combination therapy that included CDK4/6 inhibitors along with other agents was recently shown to be effective in treating castration-resistant prostate adenocarcinoma and neuroendocrine prostate cancer in vitro and in vivo [17]. Given the current understanding of CDK4's role in many cancers, it seems logical that a downregulation of CDK4 would help arrest the overactive cell cycle in the LNCaP cells.

FasL is a transmembrane protein that is part of the TNF receptor superfamily $[18,19]$. FasL interactions with the Fas receptor have been well characterized as a trigger for apoptosis $[19,20]$. Past studies have also suggested other non-apoptotic functions for FasL. Kolben et al. found that reverse FasL signaling in an in vitro assay of breast cancer cells resulted in a significant increase in apoptosis [19]. It is unclear which FasL mechanism may be at play in our study, but we did observe a clear correlation in increased apoptosis of LNCaP cells alongside an increase in FasL expression.

Considering the preferential binding SARS-CoV-2 spike protein has for ACE2 receptors, it is interesting to note that in addition to the high expression of ACE2 receptors in the lungs, several studies have found increased expression of ACE2 receptors in the prostate epithelium, kidneys, and testes, showing that the male genitourinary system may serve as a target-rich environment for SARS-CoV-2 spike protein binding [21-24]. In their review on the effects of COVID19 on the male reproductive system, He et al. found damage to testicular cells and impaired spermatogenesis and proposed that the pathology is due to both direct interactions of SARS-CoV-2 and ACE2 receptors, as well as systemic inflammatory and immune responses to infection [22].

This being an in vitro study, there were several inherent limitations. Our study focused only on a single cell line, $\mathrm{LNCaP}$, however our lab continues to conduct ongoing research investigating the effects of SARS-CoV-2 SP in various cell lines that include lung and cervical cancer cell lines. Our lab's currently unpublished data demonstrates a similar inhibition of cancer growth in the cervical cancer cell line $\mathrm{SiHa}$, via molecular mechanisms that appear to be distinct from what was observed in the $\mathrm{LNCaP}$ cell line. Another limitation was our inability to explore the interactions between SARS-CoV-2 SP and prostate cancer cells in the context of the body's inflammatory response, which has demonstrated widespread implications for the disease process of COVID-19, as well as several forms of cancer. The clinical utility of this data is also tempered by the fact that there still remains uncertainty as to how widely the SARS-CoV-2 spike protein distributes following vaccination, and for how long.

In summary, our study demonstrated that SARS-CoV-2 spike protein reduced the survival of prostate cancer cells through inhibition of proliferation and promotion of apoptosis. Our data indicates that the mechanisms included downregulation of pro-proliferative molecule CDK4 and upregulation of pro-apoptotic molecule FasL. These results suggest a potential additional benefit of COVID-19 vaccination by providing a means of exposing prostate cancer cells to SARS-CoV-2 spike protein. Though these results appear reassuring in the context of cancer patients and COVID-19 vaccine administration, much more investigation will need to be conducted before any definitive conclusions can be drawn. Nevertheless, our study is another early step to shed further light on the interactions that SARS-CoV-2 has with cancer cells. It is our hope that our findings spark further inquiry into the safety and efficacy of the COVID-19 vaccine for cancer patients, as well as provide further insight on future novel therapeutic approaches for patients with prostate cancer.

Acknowledgements This work was supported by the grant from Des Moines University for Yujiang Fang, M.D., Ph.D.

Funding This study was supported by grants for Yujiang Fang (Iowa Science Foundation Grant ISF 16-8, IOER 05-14-01, IOER 112-3749 and IOER 112-3104).

\section{Declarations}

Conflict of interest The authors have no conflict of interest.

Ethical approval This article does not contain any studies with human participants or animals performed by any of the authors.

\section{References}

1. Umakanthan S, Sahu P, Ranade AV, Bukelo MM, Rao JS, Abrahao-Machado LF, et al. Origin, transmission, diagnosis and management of coronavirus disease 2019 (COVID-19). Postgrad 
Med J. 2020;96(1142):753-8. https://doi.org/10.1136/postgradme dj-2020-138234.

2. Han HJ, Nwagwu C, Anyim O, Ekweremadu C, Kim S. COVID19 and cancer: from basic mechanisms to vaccine development using nanotechnology. Int Immunopharmacol. 2021;90:107247.

3. Pilishvili T, Fleming-Dutra KE, Farrar JL, Gierke R, Mohr NM, Talan DA, et al. Interim estimates of vaccine effectiveness of Pfizer-BioNTech and Moderna COVID-19 vaccines among health care personnel-33 US Sites, January-March 2021. Morb Mortal Wkly Rep. 2021;70(20):753.

4. Lopez Bernal J, Andrews N, Gower C, Gallagher E, Simmons R, Thelwall S, et al. Effectiveness of Covid-19 vaccines against the B.1.617.2 (delta) variant. N Engl J Med. 2021;385(7):585-94. https://doi.org/10.1056/NEJMoa2108891.

5. Curigliano G, Eggermont AM. Adherence to COVID-19 vaccines in cancer patients: promote it and make it happen! Eur J Cancer. 2021;153:257-9.

6. Geisslinger F, Vollmar AM, Bartel K. Cancer patients have a higher risk regarding COVID-19-and vice versa? Pharmaceuticals. 2020;13(7):143.

7. Ribas A, Sengupta R, Locke T. AACR COVID-19 and cancer task force, priority COVID-19 vaccination for patients with cancer while vaccine supply is limited. Cancer Discov. 2020;11:233-6.

8. Kuderer NM, Choueiri TK, Shah DP, Shyr Y, Rubinstein SM, Rivera DR, et al. Clinical impact of COVID-19 on patients with cancer (CCC19): a cohort study. Lancet. 2020;395(10241):190718. https://doi.org/10.1016/S0140-6736(20)31187-9.

9. Saini KS, Martins-Branco D, Tagliamento M, Vidal L, Singh N, Punie K, et al. Emerging issues related to COVID-19 vaccination in patients with cancer. Berlin: Springer; 2021.

10. Siegel RL, Miller KD, Fuchs HE, Jemal A. Cancer statistics, 2021. CA Cancer J Clin. 2021;71(1):7-33. https://doi.org/10.3322/caac. 21654.

11. Ding VA, Zhu Z, Steele TA, Wakefield MR, Xiao H, Balabanov $\mathrm{D}$, et al. The novel role of IL-37 in prostate cancer: evidence as a promising radiosensitizer. Med Oncol (Northwood, London, England). 2017;35(1):6. https://doi.org/10.1007/s12032-017-1070-7.

12. Schroeder AC, Xiao H, Zhu Z, Li Q, Bai Q, Wakefield MR, et al. A potential role for green tea as a radiation sensitizer for prostate cancer. Pathol Oncol Res. 2019;25(1):263-8. https://doi.org/10. 1007/s12253-017-0358-4.

13. Xiao H, Alisic H, Reiman BT, Deng Z, Zhu Z, Givens NT, et al. IL-39 reduces proliferation and promotes apoptosis of bladder cancer by altering the activity of cyclin $\mathrm{E}$ and Fas. Anticancer Res. 2021;41(5):2239-45. https://doi.org/10.21873/anticanres.15000.

14. Zhu Z, Davidson KT, Brittingham A, Wakefield MR, Bai Q, Xiao $\mathrm{H}$, et al. Trichomonas vaginalis: a possible foe to prostate cancer.
Med Oncol (Northwood, London, England). 2016;33(10):115. https://doi.org/10.1007/s12032-016-0832-y.

15. Malumbres M, Barbacid M. Cell cycle, CDKs and cancer: a changing paradigm. Nat Rev Cancer. 2009;9(3):153-66. https:// doi.org/10.1038/nrc2602.

16. Sheppard KE, McArthur GA. The cell-cycle regulator CDK4: an emerging therapeutic target in melanoma. Clin Cancer Res. 2013;19(19):5320-8. https://doi.org/10.1158/1078-0432. CCR-13-0259.

17. Wu C, Peng S, Pilie PG, Geng C, Park S, Manyam GC, et al. PARP and CDK4/6 inhibitor combination therapy induces apoptosis and suppresses neuroendocrine differentiation in prostate cancer. Mol Cancer Ther. 2021. https://doi.org/10.1158/1535-7163. MCT-20-0848.

18. Sun M, Ames KT, Suzuki I, Fink PJ. The cytoplasmic domain of Fas ligand costimulates TCR signals. J Immunol. 2006;177(3):1481-91. https://doi.org/10.4049/jimmunol.177.3. 1481.

19. Kolben T, Jeschke U, Reimer T, Karsten N, Schmoeckel E, Semmlinger A, et al. Induction of apoptosis in breast cancer cells in vitro by Fas ligand reverse signaling. J Cancer Res Clin Oncol. 2018;144(2):249-56. https://doi.org/10.1007/s00432-017-2551-y.

20. Peter ME, Budd RC, Desbarats J, Hedrick SM, Hueber AO, Newell MK, et al. The CD95 receptor: apoptosis revisited. Cell. 2007;129(3):447-50. https://doi.org/10.1016/j.cell.2007.04.031.

21. Fan C, Lu W, Li K, Ding Y, Wang J. ACE2 expression in kidney and testis may cause kidney and testis infection in COVID-19 patients. Front Med. 2021;7:1045.

22. He Y, Wang J, Ren J, Zhao Y, Chen J, Chen X. Effect of COVID19 on male reproductive system: a systematic review. Front Endocrinol (Lausanne). 2021;12: 677701. https://doi.org/10.3389/ fendo.2021.677701.

23. Shen Q, Xiao X, Aierken A, Yue W, Wu X, Liao M, et al. The ACE2 expression in Sertoli cells and germ cells may cause male reproductive disorder after SARS-CoV-2 infection. J Cell Mol Med. 2020;24(16):9472-7.

24. Wang Z, Xu X. scRNA-seq profiling of human testes reveals the presence of the ACE2 receptor, a target for SARS-CoV-2 infection in Spermatogonia, Leydig and Sertoli cells. Cells. 2020;9(4):920. https://doi.org/10.3390/cells9040920.

Publisher's Note Springer Nature remains neutral with regard to jurisdictional claims in published maps and institutional affiliations. 